Editorial

Mirando hacia el futuro

\title{
Looking to the future
}

\author{
María Jesús Terradillos García \\ Directora de la Escuela Nacional de Medicina del Trabajo. Instituto de Salud Carlos III. Madrid. España. \\ Recibido: 14-05-2019 \\ Aceptado: 30-05-2019
}

A través de este medio me permito presentarme como nueva Directora de la Escuela Nacional de Medicina del Trabajo (ENMT). Como médico especialista en esta disciplina, emprendo esta nueva etapa profesional con ilusión y optimismo, pero también con humildad.

Ilusión por la oportunidad que se me brinda de participar en el desarrollo de las actividades y cometidos que la Escuela tiene encomendados y cuyo objetivo final es el contribuir a alcanzar el más alto grado de bienestar físico, psíquico y social de los trabajadores, evitando que el mero hecho de desempeñar una actividad laboral pueda ocasionar un daño a su salud. Dicho objetivo no es otro que el de la propia especialidad de Medicina del Trabajo y para alcanzarlo la ENMT es el organismo referente en formación especializada y continuada, investigación, asesoramiento y divulgación científica en materia de salud laboral.

Optimismo porque, a pesar de las dificultades y del tortuoso recorrido que ha seguido nuestra especialidad, tan diferente al de otras especialidades clínicas, en los últimos años estamos asistiendo al reconocimiento y valoración del profesional en salud laboral, incluyendo pero sin ser exclusivos tanto a la medicina y enfermería del trabajo como a la prevención de riesgos laborales. Esta consideración conlleva así mismo la catalogación de su labor como imprescindible en la salud laboral y la mejora de las condiciones de trabajo para evitar que éstas supongan un riesgo para la salud de los trabajadores. Por otra parte, el largo camino experimentado por la Medicina del Trabajo desde que su padre, Bernardino Ramazzini, publicara en 1700 su tratado De Morbis Artificium Diatriba, hasta nuestros días no ha sido infértil, y nos ha conducido hasta este siglo XXI en el que, en nuestro medio, las políticas de prevención de riesgos laborales forman parte del entramado y la filosofía industrial, de modo que actualmente podemos contemplar cómo avanzamos yendo un paso más allá, estableciéndose no ya únicamente planes de prevención sino de promoción de la salud en el medio laboral. Así, en España el número de empresas que obtienen la certificación de Empresa Saludable va en aumento, haciéndose tangible la preocupación que siente la sociedad actual por la salud laboral.

Y sincera humildad, ya que son los magníficos profesionales que me han precedido en su Dirección los artífices del impulso y el avance que la ENMT ha experimentado a lo largo de su historia. Así mismo, estos logros no serían posibles sin la colaboración de otras instituciones, organismos y profesionales de dentro y fuera de la Escuela que aportáis vuestros conocimientos y esfuerzo al engrandecimiento progresivo de nuestra actividad. Espero seguir aprendiendo de todos vosotros y poder contribuir en esta encomiable tarea que tenemos asignada.

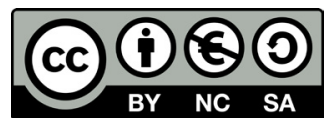

https://creativecommons.org/licenses/by-nc-sa/4.0/ 
De todos es conocida la amplia trayectoria académica de la ENMT tanto en la formación especializada de los médicos internos residentes en Medicina del Trabajo como en formación continuada principalmente en los campos de la medicina y enfermería del trabajo, la salud laboral, la prevención de riesgos laborales y la promoción de la salud. Como nuevo proyecto a corto plazo nos planteamos iniciar la formación especializada a los residentes en enfermería del trabajo (EIR) tras la reciente acreditación de unidades docentes multiprofesionales en salud laboral. Así mismo, contemplamos reforzar la formación en postgrado con la incorporación de nuevos cursos en formación continuada.

Pero no es ésta su única área de actividad: la ENMT como centro propio del Instituto de Salud Carlos III, órgano investigador por excelencia, es firme defensora del desarrollo de proyectos de investigación en Salud Laboral. La investigación es la herramienta que permite poner de manifiesto la situación de salud de la población trabajadora, relacionarla con las condiciones laborales, establecer unas conclusiones y, a partir de ahí, poner en marcha las acciones que ayuden a mejorar esta salud de la población trabajadora. Así, la ENMT desarrolla sus propias líneas de investigación, que incluyen actualmente, entre otros, los campos de ergonomía y factores humanos en lo relativo a fatiga y patrones motores como factores vinculados a la causalidad del trastorno músculoesquelético, problema que representa entre un $80 \%$ y un $90 \%$ de las enfermedades profesionales notificadas. Así mismo se investiga en fatiga de la voz profesional. De esta manera la ENMT participa en proyectos de investigación competitivos -nacionales e internacionales-. Se pretende ampliar la actividad investigadora en el área de la Salud Laboral y la Seguridad en el Trabajo; para ello se contempla la cooperación con otros centros e instituciones y así compartir recursos. Desde la Escuela apostamos por la investigación como disciplina indispensable para avanzar en el conocimiento y la evidencia científica.

En cuanto a la divulgación, llevada a cabo a través de la revista Medicina y Seguridad en el Trabajo, nuestro objetivo es consolidarla como publicación referente en salud laboral. Este año, lamentablemente, por motivos que exceden el ámbito de la ENMT y del propio ISCIII, su publicación ha permanecido estancada durante varios meses. Por fortuna, se ha reanudado con el espíritu de afianzamiento y el propósito de reforzar su impacto, aspirando a formar parte de bases como Scopus o de la Web of Science.

Esto únicamente podrá conseguirse gracias a su imprescindible contribución a través del envío de artículos, ya sea en forma de casos clínicos, trabajos de investigación o de revisión, etc. El esfuerzo impagable de todos hará posible que continúe creciendo en calidad, prestigio y difusión. Por ello, desde aquí les invito a compartir su saber y conocimientos a través de la revista, confiando en continuar recibiendo sus textos con la calidad que siempre les ha caracterizado.

Es gracias a todos, aunando esfuerzos, como conseguiremos llegar a buen puerto. 